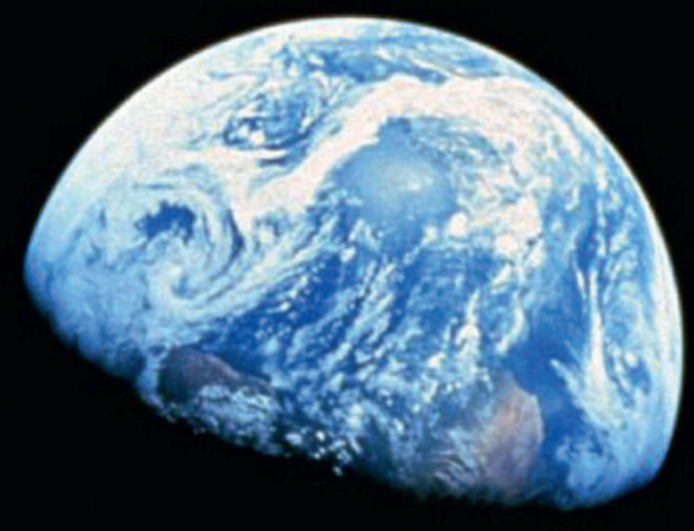

\title{
Ewige Ahnung
}

Ungebremst dreht sich die Erde wie seit hundert Ewigkeiten zieht uns mit bei jedem Schritt fort in unbekannte Weiten ...

Wo's Dich hintreibt, wo Du landest ob im Leeren - ob im Glück? Sicher ist das Eine nur: Kehrst Du um auf deiner Spur, findest nie mehr ganz zurück ...

Alles fliesset - Panta rhei: Alle Uhren ticken aus und es schlummern Zeit und Zahlen bald vergessen in Regalen still im menschenleeren Haus ...

Oben rast es ewig weiter. Unten kümmert keinen Stern. Niemand weiss, wie lang noch Ionen prallen gegen Elektronen bis es knallt - auch nicht das CERN ...

Doch es weiss, wie's einst begonnen: Als Hadronen wütend waren und zerfetzten Positronen wurde Eiweiss aus Leptonen. Mehr wird Menschheit nie erfahren ...

Auch nicht, was vor jenen Gasen, welche rasten aus den Bahnen War da Nichts im leeren Raum? Und davor ein andres Nichts - ein Traum? Oder etwas, das wir ahnen ...

\section{Constantin Schuler}

